future excavation may well fill in further detail. One point remains to be mentioned. On determination of the specific character of the Folsom point and the advancement of its claim to a high antiquity, attention was directed, as already mentioned, to the fact that it was already known, in one instance at least, having received the name of the "Seneca River point". It was shown to have a wide distribution-from southern Canada to the Gulf of Mexico and from the Rockies to the Atlantic. Further study, however, has demonstrated that the true Folsom points are confined to the High Plains on the eastern slope of the Rockies, while the more widely distributed point is a larger, more generalised form, centring notably in the Finger Lakes section of New York State, in Ohio, Tennessee and southern Virginia. The affiliation and the chronological and distributional relation of the two forms are problems which are now being made the subject of study by $\mathrm{Mr}$. Roberts.

Until the typological and chronological relations of the two forms of point are established with some degree of precision, no finality in the interpretation of the archæological evidence is attainable. Tentatively, however, it may be pointed out that the evident antiquity and the known distribution of the true Folsom point are consistent with the view that it is a specialised form developed by the people who, it has been suggested, penetrated to the south-west in the period of transition at the close of the Ice Age along a corridor on the eastern slopes of the Rockies. It will be interesting to see if the researches in Siberian archæology, upon which Mr. E. B. Howard is to engage, produce any typological evidence of an Asiatic ancestry for this remarkable American type of implement.

\title{
The Percy Sladen Expedition to Lake Huleh
}

$\mathrm{H}^{2}$ ULEH is a shallow lake lying in the northern end of the Jordan Valley, where it extends towards Mount Hermon. The sides of this valley are formed here by two parallel ranges of mountains, but at the south end of the lake the valley is closed by low hills except where the Jordan has cut a deep gorge into Lake Tiberias, the fall to which is 600 feet. The actual lake is approximately five miles long by three across, and is roughly pear-shaped, with its broad end to the north. Its maximal depths are 10-12 feet, but its greater part is not more than $4-5$ feet. On its east side the mountains, which are basaltic, commence their rise close to the lake, and the shore is rocky, much large material being carried down the numerous water-courses. On the west side, a broad plain extends out from the lake, for the strong winter torrents have brought down quantities of gravel, which form spits projecting into the lake. Over most of the central area, the bottom of the lake is of soft grey mud, which is largely populated by plants of Potamogeton. At the extreme south, there is a small area where Phragmites dominates, and this also grows on the eastern side in isolated patches. On both sides of the lake there are numerous springs, and some cold patches in the lake are supposed to mark further effluents.

The lake is bounded on its northern side by a large swamp, through which the Jordan flows as a swift stream, even in the dry season. The swamp begins as a band of floating lilies (Nuphar) across its north end, extending down each side for half a mile. On the inside of the lilies, the plant succession is at present being studied. The swamp is not homogeneous in structure, and its most striking feature is the papyrus, which over large areas is the dominant plant form. Through it, progression is only possible along waterways, which are kept open by the Arabs, who use it for many purposes. The swamp consists of a mass of roots, much matted and bound together with plant debris in various stages of decomposition. The roots appear to be floating in the water, and it is easy to sink waist deep through masses of debris, where the papyrus is not too thick. At various places clear pools are found, these apparently due to springs. At the sides of the swamp the land is being reclaimed by Arabs for the planting of maize and millet.

The channel of the Jordan runs down the middle of the northern swamp, where heavier silt has been deposited during the floods of the rainy season. Local observations suggest that the swamp is extending southwards and encroaching on the lake, almost as if pushed by the processes of reclamation on its shores. One of the most striking features of the lake is the large quantity of fine silt brought down by the Jordan, when irrigation is occurring further up the valley. It is of a light grey colour, and quite different from the mud formed by plant decomposition. It is deposited generally over the lake, and forms in addition a broad bar across its northern end. 
The rights over the lake have recently been purchased by the Palestine Land Development Co. from the Arab owners. The company has employed engineers to estimate the cost of the drainage of the lake and swamp, and is now selling it upon these estimates. Several interested companies are employing their own engineers to check these. Up to the present, no work has been commenced, but it is anticipated that the drainage, which is a simple question, will be completed in 1936 or the following year.

The biological survey of Lake Huleh is in charge of Mr. Roger Washbourn with a botanist, both from the University of Birmingham. The lake is interesting mainly in comparison with Lake Tiberias and other parts of the Rift Valley in Palestine and East Africa. The presence of animals of African affinity was shown by Annandale in 1916, and the biologists are largely concerned with investigating the fauna and flora before the lake ceases to exist. In addition, Huleh lies near the southern boundary of several palæarctic species. The ecology also of a lake with a papyrus swamp in this latitude should prove interesting. Having these objects in view, the zoological part of the work is largely the collection of animals from the varied habitats that the lake and swamp present. To define these accurately, the physical and chemical conditions are being studied, and these are, of course, a prime factor in governing the plankton. The botanist is fully occupied with his study of the swamp and the interrelations of the plants in their different habitats. The difficulty of transport is considerable-and the lake is fever-stricken-but it is hoped that an impression will be secured of the plant and animal life of an area which will soon have ceased to exist.

\section{The Chemotherapy of Malaria*}

Q UININE was discovered by Pelletier and Caventou in 1820 and was promptly manufactured in France and England in quantities sufficient to permit of its use in the treatment of malaria, in place of crude cinchona bark. This was an early and unconscious application of the principle upon which Ehrlich was to found chemotherapy ninety years later. By that time, thanks to the labours of Hesse, Skraup, Köenigs, von Miller and Rohde and Rabe, constitutional formulæ had been assigned to quinine and the other cinchona alkaloids, which Rabe and his collaborators confirmed in a series of researches culminating in the complete synthesis of dihydroquinine and dihydroquinidine in 1931. Partial syntheses had been effected some years earlier and the methods employed had been extended to the preparation of products allied to the cinchona alkaloids in type, but of simpler structure. In 1891 Grimaux and Arnaud prepared from cupreine a series of homologues of quinine, one of which, ethylcupreine, was tried clinically and found to be somewhat more active than quinine, and this first French experiment in the production of 'modified cinchona alkaloids' led to the preparation of many other substances of this type.

Chemists had in fact accumulated a mass of possible anti-malarials, the therapeutic value of which there was no practical means of testing. This want was supplied when Roehl devised his

* Based on a discussion, introduced by Col. S. P. James, in Section $B$ (Chemistry) of the British Association meeting at Norwich on September 9. Other contributors to the discussion were Prof. W Schulemann, Prof. R. Robinson, Dr. P. Tate (with Prof. Keilin and Miss M. Vincent), Dr. T. A. Henry, Sir Rickard Christophers and Prof. Warrington Yorke. technique of testing such drugs in bird malaria, using canaries for this purpose. Of the various 'leads' then available for the synthesis of new anti-malarials, Prof. Schulemann and his coworkers. Schonhofer and Wingler, selected methylene blue, which had been shown to have some action in malaria, and from this starting point they evolved plasmoquine in 1924. This was followed by atebrin, discovered by Mauss and Mietzsch in 1930.

These two drugs have one feature in common, a dialkylaminoalkylamino-side-chain, -NH-CHMe$\mathrm{CH}_{2}-\mathrm{CH}_{2}-\mathrm{CH}_{2}-\mathrm{NEt}_{2}$, attached at position 8 in 6-methoxyquinoline, in the case of plasmoquine, and at position 5 in 2-chloro-7-methoxyacridine, in the case of atebrin; but as acridine is quinoline with a benzene ring fused on, both drugs can be regarded as derived from 6-methoxyquinoline, a characteristic they share with quinine, which, however, has a different and more complex sidechain. Plasmoquine acts preferentially on the sexual forms (crescents or gametocytes) and atebrin and quinine on the asexual forms (schizonts) of the malaria parasite. Their respective actions in the various types of malaria is not as clear-cut as this brief description implies, but it is permissible now to divide anti-malarial drugs into 'anti-gametocyte', represented by plasmoquine and its allies, and 'anti-schizont', of which quinine and atebrin are types.

These discoveries have led to great activity in the synthesis of such drugs in Great Britain, France, Russia and elsewhere, and Prof. Robinson gave an account of the reactions used in the 